\title{
RESPOSTAS DA MANDIOCA À ADUBAÇÃO NPK E CALAGEM EM SOLOS ARENOSOS DO NOROESTE DO PARANÁ1
}

\author{
JONEZ FIDALSKI ${ }^{2}$
}

\begin{abstract}
RESUMO - Desenvolveram-se dois experimentos de campo, em áreas de pastagens degradadas, no período de 1991-92, nos municípios de Paranavaí e Altônia, região noroeste do Paraná, em Podzólico Vermelho-Escuro de baixa fertilidade, originários da formação geológica do arenito Caiuá, com o objetivo de avaliar as respostas da mandioca (Manihot esculenta L.) na produção de raízes e as características químicas do solo à adubação mineral NPK e à calagem. O delineamento estatístico foi em blocos casualizados, com 19 tratamentos e quatro repetições, aplicando-se nitrogênio $\left(0,20,40\right.$ e $60 \mathrm{~kg} \mathrm{ha}^{-1} \mathrm{de}$ $\mathrm{N})$, fósforo $\left(0,30,60,90\right.$ e $\left.120 \mathrm{~kg} \mathrm{ha}^{-1} \mathrm{de}_{2} \mathrm{O}_{5}\right)$, potássio $\left(0,40,80\right.$ e $120 \mathrm{~kg} \mathrm{ha}^{-1}$ de $\left.\mathrm{K}_{2} \mathrm{O}\right)$ e calcário $\left(0,850,1.700\right.$ e $\left.2.550 \mathrm{~kg} \mathrm{ha}^{-1}\right)$. A produção de raízes de mandioca não apresentou respostas à calagem, adubação nitrogenada e potássica. A adubação potássica não contribuiu para elevar os teores de K no solo. A adubação fosfatada aumentou a produção de raízes de mandioca e os teores de P no solo após o seu cultivo, sendo considerada essencial na produção de mandioca nos dois solos arenosos estudados do noroeste do Paraná.
\end{abstract}

Termos para indexação: Manihot esculenta, fósforo, rotação de culturas, calagem.

\section{CASSAVA RESPONSE TO NPK AND LIMING IN SANDY SOILS OF NORTHWEST PARANÁ, BRAZIL}

\begin{abstract}
Two field experiments were carried out during 1991-92 in Paranavaí and Altônia cities, Northwest of the State of Paraná, Brazil, in order to evaluate the yield response of cassava and soil chemical characteristics to NPK fertilizers and liming. On sandy Dark Red Podzol, soils have low fertility originated from geological formation of "Caiuá" sandstone. The experimental design was a randomized block with nineteen treatments and four replications. Treatments comprised nutrient rates of nitrogen $\left(0,20,40\right.$ and $\left.60 \mathrm{~kg} \mathrm{ha}^{-1}\right)$; phosphorus $\left(0,30,60,90\right.$ and $\left.120 \mathrm{~kg} \mathrm{ha}^{-1}\right)$; potassium $(0,40,80$ and $\left.120 \mathrm{~kg} \mathrm{ha}^{-1}\right)$; and lime $\left(0,850,1,700\right.$ and $\left.2,550 \mathrm{~kg} \mathrm{ha}^{-1}\right)$. Yield of cassava roots was not influenced by liming and nitrogen and potassium fertilization. Potassium fertilizer did not contribute to increase the soil $\mathrm{K}$ levels. The $\mathrm{P}$ fertilizing increased cassava root production, $\mathrm{P}$ content in the soil after cassava cultivation, and was considered as essential in the cassava roots production in both sandy soils of the Northwest of Paraná.

Index terms: Manihot esculenta, phosphorus, culture rotation, liming.
\end{abstract}

\section{INTRODUÇÃO}

A região do noroeste do Paraná apresenta aproximadamente $70 \%$ de sua área agrícola cultivada com pastagens que, quando degradadas, estão geralmen-

\footnotetext{
${ }^{1}$ Aceito para publicação em 21 de setembro de 1998.

${ }^{2}$ Eng. Agr., Instituto Agronômico do Paraná (IAPAR), Caixa Postal 564, CEP 87701-970 Paranavaí, PR. E-mail: fidalski@pr.gov.br
}

te infestadas com Paspalum notatum, gramínea adaptada aos solos arenosos de baixa fertilidade, mas de baixa produção forrageira. Trabalhos realizados no período de 1982 a 1991 indicaram que o plantio de culturas anuais, como o algodão e milho, por um a dois anos, seguido da plantação do pasto, é um processo adequado para a reforma de pastagens degradadas atribuídas à redução de invasoras e à elevação dos teores residuais de $\mathrm{P}$ no solo, que aumentaram a produção da forrageira (Marun \& Mella, 1994; Marun \& Mella, 1997). 
A reforma de pastagem com o cultivo de mandioca (Manihot esculenta) somente com calagem, seguindo procedimentos similares aos empregados na região noroeste do Paraná, não foi considerada uma boa opção, por manter a fertilidade do solo com baixos teores de $\mathrm{P}$ residuais no solo para a forrageira, e por propiciar a reinfestação de invasoras (Marun \& Mella, 1997).

No entanto, o cultivo de mandioca tornou-se a principal opção para a reforma de pastagem no noroeste do Paraná, geralmente na forma de arrendamento de pastagens degradadas, estimulada pelo grande número de farinheiras de mandioca instaladas na região. Essa opção é atribuída à adaptação da cultura às condições edafoclimáticas, com produção média paranaense de $22 \mathrm{t} \mathrm{ha}^{-1}$ de raízes de mandioca (Acompanhamento..., 1993), demanda de matéria prima às agroindústrias e obtenção de renda pelos fazendeiros para subsidiar a própria reforma de pastagem.

A exploração da cultura de mandioca sem adubação mineral pode comprometer o processo de reforma de pastagem, pois, segundo Howeler (1984), na produção de raízes de mandioca ocorre grande extração de nutrientes do solo. Portanto, o cultivo de mandioca no noroeste do Paraná assume caráter predatório da fertilidade do solo, acarretando pastagens mal estabelecidas, diminuição da produtividade e do valor nutricional da forragem, maior infestação por plantas invasoras, e, conseqüentemente, menor longevidade da pastagem (Ferrari Neto, 1991).

Os solos com pastagens do noroeste do Paraná, originários da formação geológica do arenito Caiuá, têm baixos teores de $\mathrm{P}$ devido, em parte, à sua exploração sem adubação mineral, apresentando 80,5\% dos resultados das análises químicas de solo inferiores a $5,8 \mathrm{mg} \mathrm{dm}^{-3}$ de P (Fidalski, 1997). A falta de estudos da nutrição da mandioca nesses solos tem contribuído para a exploração da cultura sem o emprego de adubação mineral. Tal prática poderia aumentar a produção de raízes de mandioca e assegurar o êxito do processo de reforma de pastagem com essa cultura.

O presente trabalho foi desenvolvido com o objetivo de avaliar a resposta da cultura de mandioca à adubação mineral NPK e à calagem, na produção de raízes, e as alterações das características químicas do solo após o seu cultivo, em solos arenosos originários da formação geológica Caiuá do noroeste do Paraná.

\section{MATERIAL E MÉTODOS}

Dois experimentos foram desenvolvidos em áreas anteriormente ocupadas por pastagens que precisavam de reforma, nos municípios de Paranavaí $\left(23^{\circ} 05^{\prime} \mathrm{S}\right.$ e $\left.53^{\circ} 26^{\prime} \mathrm{W}\right)$ e Altônia ( $23^{\circ} 51^{\prime} \mathrm{S}$ e $\left.53^{\circ} 53^{\prime} \mathrm{W}\right)$, noroeste do Paraná, em Podzólico Vermelho-Escuro, relevo suave-ondulado, com 8\% de declividade (Embrapa, 1984), os quais apresentavam baixa fertilidade no plantio. Suas características químicas e físicas, determinadas conforme procedimentos analíticos descritos por Pavan et al. (1992), na profundidade de 0-20 e 20-40 cm, encontram-se na Tabela 1.

Os tratamentos foram constituídos por doses de $\mathrm{N}(0$, 20, 40, $\left.60 \mathrm{~kg} \mathrm{ha}^{-1}\right)$ na forma de uréia; de $\mathrm{P}(0,30,60,90$, $\left.120 \mathrm{~kg} \mathrm{ha}^{-1}\right)$ na forma de superfosfato simples; $\mathrm{K}(0,40$, $\left.80,120 \mathrm{~kg} \mathrm{ha}^{-1}\right)$ na forma de cloreto de potássio e calcário dolomítico, nas doses de 0, 0,85, 1,70 e 2,55 tha ${ }^{-1}$, somando 19 tratamentos (Tabela 2), organizados em blocos casualizados, com quatro repetições.

$\mathrm{O}$ preparo do solo das áreas experimentais foi realizado de forma convencional com gradagem pesada, aração e grade niveladora para obter condições ideais à instalação dos experimentos.

O plantio de mandioca, cultivar Fibra, foi realizado em 11/10/91 e 11/11/91, respectivamente, em Paranavaí e Altônia. O plantio foi feito em sulcos com espaços de $0,7 \mathrm{~m}$, sendo as manivas distribuídas à distância de $0,5 \mathrm{~m}$ nos sulcos. As parcelas úteis de $6,3 \mathrm{~m}^{2}$ foram de duas fileiras de $4 \mathrm{~m}$, correspondendo a 16 plantas, com bordadura comum entre as parcelas, constituídas de uma planta na linha de plantio e uma fileira entre os blocos.

A calagem foi realizada no dia do plantio, distribuindose o calcário a lanço e incorporando-o com enxada à profundidade de $0-20 \mathrm{~cm}$. Os adubos fosfatado $(100 \% \mathrm{da}$ dose) e potássico (50\% da dose) foram distribuídos nos sulcos de plantio e recobertos com fina camada de solo para evitar o contato direto com as manivas de mandioca.

As adubações potássica e nitrogenada foram parceladas em duas vezes, visando reduzir possíveis perdas por lixiviação desses nutrientes, dada a textura arenosa dos solos. A primeira adubação em cobertura com N $(50 \%$ da dose) e o restante do $\mathrm{K}$ foram aplicados 30 dias após o plantio. A segunda adubação em cobertura foi realizada somente com N (50\% da dose), 90 dias após a emergência das plantas.

A condução da cultura exigiu capinas manuais na fase inicial de desenvolvimento vegetativo, para o controle de plantas daninhas e brotação de gramíneas. As avaliações da produção de raízes da mandioca foram realizadas nas parcelas úteis, nove e dez meses após o plantio, respectivamente, em Altônia e Paranavaí. 
TABELA 1. Características químicas e físicas de amostras do Podzólico Vermelho-Escuro textura média, na instalação dos experimentos de Paranavaí e Altônia em 1991.

\begin{tabular}{|c|c|c|c|c|c|c|c|c|c|c|c|c|c|}
\hline Profund. & $\mathrm{pH}$ & $\mathrm{P}$ & $\mathrm{C}$ & $\mathrm{Ca}$ & $\mathrm{Mg}$ & $\mathrm{K}$ & A1 & $\mathrm{H}+\mathrm{Al}$ & $\mathrm{T}$ & \multirow{2}{*}{$\begin{array}{c}\mathrm{V} \\
(\%) \\
\end{array}$} & Areia & Silte & Argila \\
\hline$(\mathrm{cm})$ & $\left(\mathrm{CaCl}_{2}\right)$ & $\left(\mathrm{mg} \mathrm{dm}^{-3}\right)$ & $\left(\mathrm{g} \mathrm{dm}^{-3}\right)$ & \multicolumn{6}{|c|}{ - $\left(\mathrm{mmol}_{\mathrm{c}} \mathrm{dm}^{-3}\right)$} & & \multicolumn{3}{|c|}{ - $\left(\mathrm{g} \mathrm{kg}^{-1}\right)$----- } \\
\hline \multicolumn{14}{|c|}{ Paranava } \\
\hline $0-20$ & 4,6 & 1,9 & 9,3 & 15,4 & 7,0 & 2,1 & 1,2 & 33,3 & 57,8 & 42,4 & 89 & 1 & 10 \\
\hline $20-40$ & 4,7 & 1,4 & 7,2 & 15,9 & 7,0 & 2,0 & 1,4 & 29,3 & 54,2 & 45,9 & 88 & 1 & 11 \\
\hline \multicolumn{14}{|c|}{ Altônia } \\
\hline $0-20$ & 4,5 & 3,1 & 7,4 & 10,9 & 8,1 & 1,1 & 3,9 & 37,2 & 57,3 & 35,1 & 83 & 2 & 15 \\
\hline $20-40$ & 4,0 & 2,5 & 6,2 & 6,6 & 4,6 & 0,7 & 8,2 & 45,2 & 57,1 & 20,8 & 80 & 2 & 18 \\
\hline
\end{tabular}

TABELA 2. Relação dos 19 tratamentos de adubação mineral NPK e calagem.

\begin{tabular}{crrrr}
\hline Tratamento & $\mathrm{N}$ & $\mathrm{P}_{2} \mathrm{O}_{5}$ & $\begin{array}{r}\mathrm{K}_{2} \mathrm{O} \\
\left(\mathrm{kg} \mathrm{ha}^{-1}\right)\end{array}$ & Calcário \\
\hline 1 & 0 & 0 & 0 & 0 \\
2 & 0 & 0 & 0 & 850 \\
3 & 0 & 0 & 0 & 1.700 \\
4 & 0 & 0 & 0 & 2.550 \\
5 & 40 & 90 & 80 & 0 \\
6 & 40 & 90 & 80 & 850 \\
7 & 40 & 90 & 80 & 1.700 \\
8 & 40 & 90 & 80 & 2.550 \\
9 & 0 & 90 & 80 & 0 \\
10 & 20 & 90 & 80 & 0 \\
11 & 60 & 90 & 80 & 0 \\
12 & 40 & 0 & 80 & 0 \\
13 & 40 & 30 & 80 & 0 \\
14 & 40 & 60 & 80 & 0 \\
15 & 40 & 120 & 80 & 0 \\
16 & 40 & 90 & 0 & 0 \\
17 & 40 & 90 & 40 & 0 \\
18 & 40 & 90 & 120 & 0 \\
19 & 0 & 90 & 0 & 0 \\
\hline
\end{tabular}

Para a avaliação da fertilidade do solo após a colheita das raízes de mandioca, foram coletadas amostras de solo a 0-20 cm de profundidade. Cada uma foi composta de 20 subamostras em cada parcela útil, coletadas em quatro pontos eqüidistantes nas duas linhas de plantio (8 subamostras), e em três entrelinhas da parcela (12 subamostras).

Os resultados de produção de raízes de mandioca e as características químicas do solo após o seu cultivo foram submetidas às análises de variância dos 19 tratamentos. Os resultados foram também submetidos à análise de regressão em função das doses de N, P, K e calcário. Todas as análises foram realizadas individualmente em cada um dos experimentos.

\section{RESULTADOS E DISCUSSÃO}

A adubação fosfatada aumentou significativamente a produção de raízes de mandioca em $28 \%$ e $39 \%$, com a dose de $120 \mathrm{~kg} \mathrm{ha}^{-1} \mathrm{de}_{2} \mathrm{O}_{5}$, respectivamente, em Altônia e Paranavaí, observando-se a resposta máxima da produção com $100,98 \mathrm{~kg} \mathrm{ha}^{-1} \mathrm{de}$ $\mathrm{P}_{2} \mathrm{O}_{5}$ em Paranavaí e linear em Altônia (Fig.1), obtidas dos tratamentos 12,13,14, 5 e 15 (Tabelas 2 e 3). Tais incrementos na produção de raízes de mandioca têm relação com os baixos teores de P no solo na ocasião do plantio, observando-se maiores respostas quanto menor o teor de P. Essas respostas estão de acordo com o estudo dos experimentos realizados por Gomes (1987), apontando o P como o elemento de maior importância no aumento da produção de raízes.

A adubação fosfatada elevou os teores de $\mathrm{P}$ no solo após a colheita de raízes de mandioca em relação aos teores originais no solo (Tabela 3 ). Teores adequados de $\mathrm{P}$ são fundamentais para o estabelecimento das forrageiras após a rotação de culturas na reforma de pastagens (Marun \& Mella, 1994; Hoffmann et al., 1995; Marun \& Mella, 1997). A recuperação parcial da fertilidade do solo por meio da adubação fosfatada no cultivo de mandioca em solos originários do arenito Caiuá do Paraná foi expressiva, considerando-se os baixos teores de P disponíveis nas áreas de pastagens (Fidalski, 1997).

A inexistência de estudos de calibração de $\mathrm{P}$ para as forrageiras em solos arenosos do noroeste do Paraná tem levado técnicos a utilizarem diferentes métodos para a recomendação de adubação fosfatada, com a finalidade de elevar os baixos 
teores de P do solo. Corsi \& Nussio (1993) recomendam $50 \mathrm{~kg} \mathrm{ha}^{-1}$ de superfosfato simples para a elevação de $1 \mathrm{mg} \mathrm{dm}^{-3}$ de $\mathrm{P}$ no solo. Baseando-se nas análises de regressões lineares dos tratamentos de doses crescentes de $\mathrm{P}$ (números 12, 13, 14, 5 e 15) e dos teores deste nutriente no solo após o cultivo de mandioca em Paranavaí $\left(Y=1,8+0,074 \mathrm{X} ; \mathrm{R}^{2}=0,95^{* *}\right)$ e Altônia $\left(Y=2,5+0,099 X ; R^{2}=0,80 *\right)$, seriam necessários 50,51 e 67,57 kg de superfosfato simples para a elevação de $1 \mathrm{mg} \mathrm{dm}^{-3}$ no solo, respectivamente para Altônia e Paranavaí.

Não houve respostas da mandioca às doses crescentes de calcário com ou sem adubação NPK, tratamentos 1 a 4 e 5 a 8 , respectivamente (Tabela 3 ). As disponibilidades iniciais de 19,0 e 22,4 $\mathrm{mmol}_{\mathrm{c}} \mathrm{dm}^{-3} \mathrm{de}$ $\mathrm{Ca}$ e $\mathrm{Mg}$, respectivamente, em Paranavaí e Altônia (Tabela 1), atenderam às necessidades nutricionais da cultura, estabelecida em $20,0 \mathrm{mmol}_{\mathrm{c}} \mathrm{dm}^{-3} \mathrm{de} \mathrm{Ca} \mathrm{e}$ $\mathrm{Mg}$ (Gomes, 1987). A falta de resposta à calagem também se deve à tolerância desta cultura à saturação em Al de até 80\% (Lozano et al., 1983). Nas áreas experimentais, esses valores estavam inferiores em $5 \%$ e $20 \%$, respectivamente, em Paranavaí e Altônia, conforme os resultados das análises de solo a 0-20 cm de profundidade (Tabela 1), caracterizando solo pouco ácido à cultura, e portanto, com baixo potencial de resposta à calagem.

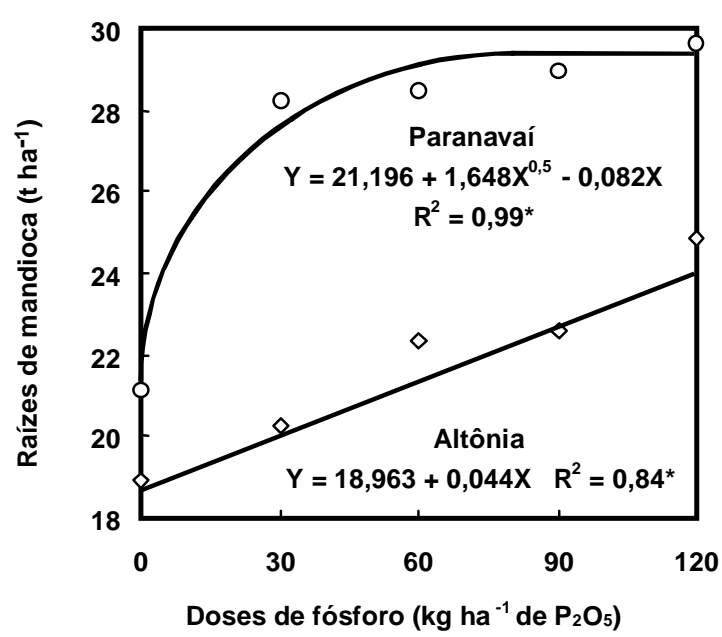

FIG. 1. Produção média de raízes de mandioca, em Paranavaí e Altônia, em função das doses de fósforo.
A calagem do solo de Paranavaí elevou significativamente a saturação por bases $(\mathrm{V})$ nos tratamentos em que foram aplicadas 1,70 e 2,55 tha ${ }^{-1}$ de calcário com e sem adubação NPK, elevando também os teores de $\mathrm{Mg}$ com 1,70 e 2,55 t ha ${ }^{-1}$ de calcário sem adubação e com $2,55 \mathrm{t} \mathrm{ha}^{-1}$ de calcário com adubação, em relação ao tratamento testemunha. Essas características químicas do solo não apresentaram diferenças estatísticas no experimento de Altônia (Tabela 3). A correção do solo não trouxe benefícios à cultura de mandioca em solos arenosos do noroeste do Paraná. Portanto, o manejo regional da correção do solo no cultivo de mandioca se deve ao fato de a cultura exigir um preparo de solo que permita a incorporação do calcário, justificada pela baixa disponibilidade de $\mathrm{Ca}$ e $\mathrm{Mg}$ no solo e a possibilidade de efetuar essa operação no processo de reforma de pastagem, condição não encontrada após o retorno e estabelecimento das forrageiras.

Após o cultivo de mandioca, os teores de C apresentaram valores médios de 7,3 e $6,1 \mathrm{~g} \mathrm{dm}^{-3}$, inferiores aos valores observados antes do plantio de 9,3 e $7,4 \mathrm{~g} \mathrm{dm}^{-3}$, respectivamente, em Paranavaí e Altônia (Tabelas 1 e 3 ). Tal decréscimo se deve ao revolvimento e exposição das áreas de pastagens para o cultivo de lavouras anuais (Cardoso et al., 1992; Marun, 1996; Fidalski, 1997), resultante da oxidação da matéria orgânica e liberação de N à mandioca, fato este atribuído à falta de resposta na produção de raízes de mandioca à adubação nitrogenada dos tratamentos 9, 10, 5 e 11 (Tabela 3). A capacidade de troca catiônica (T) dos solos paranaenses são altamente dependentes dos teores de C (Pavan et al., 1985). A redução dos teores de $C$ com o cultivo de mandioca restringe o uso intensivo dos solos arenosos do noroeste do Paraná, devendo atender à aptidão desses solos com o retorno de uma forrageira após o cultivo com lavoura anual que promova rápida cobertura e proteção à superfície do solo (Cardoso et al., 1992; Faquin et al., 1995; Hoffmann et al., 1995; Marun, 1996).

A adubação potássica não aumentou a produção de raízes de mandioca, tratamentos $16,17,5$ e 18, devido aos teores iniciais de K no solo do plantio de 2,1 e 1,1 $\mathrm{mmol}_{\mathrm{c}} \mathrm{dm}^{-3}$ que foram suficientes para a cultura (Tabela 1). Entretanto, eles diminuíram após a colheita de raízes de mandioca, para valores médios 
TABELA 3. Produção de raízes de mandioca e características químicas de amostras dos solos após os cultivos de mandioca em Paranavaí e Altônia, em função dos tratamentos.

\begin{tabular}{|c|c|c|c|c|c|c|c|c|c|c|c|c|c|c|}
\hline \multirow{2}{*}{$\begin{array}{c}\text { Trat. } \\
\mathrm{n}^{\mathrm{o}}\end{array}$} & \multicolumn{7}{|c|}{ Paranavaí } & \multicolumn{7}{|c|}{ Altônia } \\
\hline & $\begin{array}{l}\text { Raízes } \\
\left(\mathrm{kg} \mathrm{ha}^{-1}\right)\end{array}$ & $\begin{array}{c}\mathrm{P} \\
\left(\mathrm{mg} \mathrm{dm}^{-3}\right)\end{array}$ & $\begin{array}{c}\mathrm{C} \\
\left(\mathrm{g} \mathrm{dm}^{-3}\right)\end{array}$ & $\begin{array}{l}\mathrm{Ca} \\
----(\mathrm{mr}\end{array}$ & $\begin{array}{c}\mathrm{Mg} \\
\mathrm{nmol}_{\mathrm{c}} \mathrm{dm}^{-3}\end{array}$ & $\begin{array}{r}\mathrm{K} \\
\left.-{ }^{-3}\right)-\mathbf{-}^{-}\end{array}$ & $\begin{array}{c}\mathrm{V} \\
(\%)\end{array}$ & $\begin{array}{l}\text { Raízes } \\
\left(\mathrm{kg} \mathrm{ha}^{-1}\right)\end{array}$ & $\begin{array}{c}\mathrm{P} \\
\left(\mathrm{mg} \mathrm{dm}^{-3}\right)\end{array}$ & $\begin{array}{c}\mathrm{C} \\
\left(\mathrm{g} \mathrm{dm}^{-3}\right)\end{array}$ & $\mathrm{Ca}$ & $\begin{array}{c}\mathrm{Mg} \\
\mathrm{mol}_{\mathrm{c}} \mathrm{dn}\end{array}$ & K & $\begin{array}{l}\mathrm{V} \\
(\%)\end{array}$ \\
\hline 1 & 25.156 & 2,6 & 6,9 & 12,2 & 5,5 & 1,0 & 36,5 & 19.000 & 2,1 & 6,5 & 11,5 & 9,0 & 0,7 & 37,5 \\
\hline 2 & 25.188 & 2,3 & 8,0 & 14,5 & 9,0 & 1,2 & 45,0 & 14.875 & 2,1 & 6,4 & 13,7 & 10,8 & 0,7 & 44,1 \\
\hline 3 & 26.188 & 2,3 & 7,1 & 18,2 & 11,0 & 1,2 & 54,1 & 17.688 & 2,2 & 6,0 & 12,5 & 10,9 & 0,6 & 44,5 \\
\hline 4 & 26.688 & 2,4 & 7,0 & 17,5 & 12,1 & 1,0 & 55,5 & 16.938 & 2,2 & 5,6 & 12,7 & 11,3 & 0,6 & 45,6 \\
\hline 5 & 29.438 & 9,2 & 7,7 & 14,3 & 4,5 & 1,4 & 37,5 & 21.438 & 9,4 & 5,8 & 10,5 & 6,4 & 0,8 & 33,1 \\
\hline 6 & 28.688 & 6,1 & 7,4 & 14,9 & 7,4 & 1,6 & 45,1 & 23.563 & 7,2 & 6,6 & 15,2 & 10,0 & 0,7 & 44,9 \\
\hline 7 & 23.563 & 15,5 & 7,8 & 19,2 & 8,5 & 1,2 & 50,4 & 24.625 & 10,7 & 6,1 & 14,1 & 10,4 & 0,9 & 45,0 \\
\hline 8 & 28.938 & 17,7 & 6,5 & 19,6 & 11,6 & 1,4 & 57,9 & 22.563 & 6,4 & 5,8 & 15,0 & 10,6 & 0,7 & 46,5 \\
\hline 9 & 27.250 & 12,0 & 7,0 & 14,0 & 4,8 & 1,3 & 37,3 & 21.875 & 7,3 & 6,0 & 10,9 & 7,3 & 0,8 & 35,0 \\
\hline 10 & 28.875 & 9,5 & 6,9 & 13,3 & 4,9 & 1,5 & 38,6 & 20.438 & 11,5 & 5,9 & 12,7 & 7,7 & 0,7 & 38,7 \\
\hline 11 & 27.625 & 9,5 & 7,3 & 12,7 & 4,1 & 1,2 & 35,4 & 21.875 & 13,6 & 6,2 & 12,3 & 7,1 & 0,7 & 36,0 \\
\hline 12 & 21.125 & 2,6 & 7,3 & 11,7 & 6,6 & 1,5 & 40,0 & 18.938 & 2,2 & 6,2 & 10,7 & 9,1 & 0,9 & 37,2 \\
\hline 13 & 28.250 & 3,2 & 7,7 & 12,7 & 5,8 & 1,4 & 38,4 & 20.250 & 4,1 & 6,0 & 12,4 & 8,3 & 0,8 & 39,8 \\
\hline 14 & 28.500 & 5,5 & 8,2 & 13,5 & 5,4 & 1,3 & 37,9 & 22.375 & 12,5 & 6,6 & 10,8 & 6,2 & 1,0 & 30,7 \\
\hline 15 & 29.625 & 10,7 & 7,7 & 14,6 & 5,2 & 1,3 & 39,0 & 24.875 & 14,4 & 6,4 & 12,4 & 7,1 & 0,8 & 36,9 \\
\hline 16 & 30.563 & 7,8 & 6,8 & 12,7 & 4,8 & 1,3 & 37,6 & 22.500 & 10,7 & 5,8 & 10,5 & 6,8 & 0,6 & 33,2 \\
\hline 17 & 30.250 & 7,6 & 7,2 & 14,3 & 4,1 & 1,2 & 37,1 & 25.250 & 14,5 & 6,0 & 13,4 & 7,2 & 0,8 & 38,8 \\
\hline 18 & 24.875 & 15,1 & 7,5 & 14,2 & 4,7 & 1,5 & 38,2 & 23.500 & 8,5 & 5,6 & 10,2 & 6,3 & 0,8 & 32,0 \\
\hline 19 & 26.438 & 11,1 & 7,5 & 14,4 & 4,9 & 1,1 & 38,2 & 21.938 & 11,1 & 6,5 & 13,8 & 8,4 & 0,7 & 41,5 \\
\hline Média & 27.222 & 8,0 & 7,3 & 14,7 & 6,6 & 1,3 & 42,1 & 21.289 & 8,0 & 6,1 & 12,4 & 8,5 & 0,7 & 39,0 \\
\hline $\mathrm{CV}(\%)$ & 12 & 59,2 & 13,7 & 15,6 & 19,2 & 23,1 & 9,8 & 17 & 60,1 & 11,1 & 19,8 & 23,0 & 19,0 & 18,8 \\
\hline $\mathrm{dms}^{1}$ & 8,347 & 12,4 & 2,6 & 6,0 & 3,3 & 0,8 & 10,8 & 9321 & 12,6 & 1,8 & 6,4 & 5,1 & 0,4 & 19,2 \\
\hline Tukey & $*$ & $*$ & & $*$ & * & & $*$ & $*$ & & & & * & $*$ & \\
\hline
\end{tabular}


de 1,3 e 0,7 $\mathrm{mmol}_{\mathrm{c}} \mathrm{dm}^{-3}$, respectivamente, em Paranavaí e Altônia (Tabela 3), devido provavelmente à elevada extração de $\mathrm{K}$, que segundo Howeler (1984) é o nutriente extraído em maior quantidade pela cultura de mandioca. Respostas a esse nutriente são observadas em áreas sob cultivo contínuo devido à redução das reservas do solo pela elevada remoção de $\mathrm{K}$, tornando-se indispensável a sua reposição (Chan, 1984; Howeler, 1991).

Os resultados da análise dos teores de C e K no solo podem indicar que se fosse realizado outro cultivo nas áreas experimentais, provavelmente a cultura exigiria adubação com o $\mathrm{N}$ e o K ou acentuaria a redução daqueles no solo.

Estudos em casa de vegetação com Latossolo Vermelho-Escuro do noroeste do Paraná, coletado após o cultivo de mandioca, apresentando $5 \mathrm{mg} \mathrm{dm}^{-3}$ de $\mathrm{P} ; 11 \mathrm{mmol}_{\mathrm{c}} \mathrm{dm}^{-3}$ de $\mathrm{Ca} ; 3 \mathrm{mmol}_{\mathrm{c}} \mathrm{dm}^{-3}$ de $\mathrm{Mg}$ e $0,8 \mathrm{mmol}_{\mathrm{c}} \mathrm{dm}^{-3}$ de $\mathrm{K}$, utilizando-se o colonião (Panicum maximum) e braquiária (Brachiaria decumbens), revelaram a incapacidade desse solo em suprir as necessidades nutricionais em NPK, respostas crescentes a esses nutrientes quando adicionados ao solo, e à capacidade do solo em fornecer Ca e Mg às plantas (Ferrari Neto, 1991; Faquin et al., 1995; Hoffmann et al., 1995).

Os resultados em Paranavaí e Altônia ressaltam a essencialidade da adubação fosfatada, não sendo necessário realizar a calagem e adubações nitrogenadas e potássicas no cultivo da mandioca em solos do arenito Caiuá do Paraná com características semelhantes às que foram estudadas nas duas áreas experimentais.

\section{CONCLUSÕES}

1. A adubação fosfatada aumenta a produção de raízes de mandioca e os teores de $\mathrm{P}$ no solo após o cultivo de mandioca.

2. A calagem e a adubação nitrogenada e potássica não aumentam a produção de raízes de mandioca.

3. A adubação potássica não aumenta o teor de $\mathrm{K}$ no solo após o cultivo de mandioca.

\section{AGRADECIMENTOS}

Ao pesquisador Mário Takahashi e ao Técnico Agrícola Ivan César Ferrari, pelas contribuições na condução e avaliações dos experimentos; ao Sr. Ivo
Pierin (Fazenda Tarumã, Paranavaí, PR) e à Cooperativa dos Cafeicultores e Agropecuaristas de Maringá Ltda. (COCAMAR - Indústria de Fécula de Mandioca, Altônia, PR), que colaboraram com a cessão das áreas experimentais, possibilitando o desenvolvimento dos experimentos nas condições regionais de uso e manejo do solo.

\section{REFERÊNCIAS}

ACOMPANHAMENTO DA SITUAÇÃO AGROPECUÁRIA DO PARANÁ. Curitiba: DERAL/CEPA/ PR, v.19, n.8, p.160-167, set./out. 1993.

CARDOSO, A.; POTTER, R.O.; DEDECEK, R.A. Estudo comparativo da degradação de solos pelo uso agrícola no noroeste do Paraná. Pesquisa Agropecuária Brasileira, Brasília, v.27, n.2, p.349-353, fev. 1992.

CHAN, S.K. Considerações sobre a fertilidade a longo prazo na produção de mandioca. In: SEMINÁRIO DE PRÁTICAS CULTURAIS DA MANDIOCA, 1., 1980, Salvador. Anais... Brasília: Embrapa-DDT, 1984. p.135-149. (Embrapa-DDT. Documentos, 14).

CORSI, M.; NUSSIO, L.G. Manejo do capim-elefante: correção e adubação do solo. In: SIMPÓSIO SOBRE MANEJO DA PASTAGEM, 10., 1992, Piracicaba. Anais... Piracicaba: FEALQ, 1993. p.87115.

EMBRAPA. Serviço Nacional de Levantamento e Conservação de Solos. (Rio de Janeiro, RJ). Levantamento de reconhecimento dos solos do Estado do Paraná. Londrina: Embrapa-SNLCS/SUDESUL/ IAPAR, 1984. v.1/2, 791p. (Embrapa-SNLCS. Boletim de pesquisa, 27; IAPAR. Boletim técnico, 16).

FAQUIN, V.; HOFFMANN, C.R.; EVANGELISTA, A.R.; GUEDES, G.A.A. O potássio e o enxofre no crescimento da braquiária e do colonião em amostras de um latossolo da região noroeste do Paraná. Revista Brasileira de Ciência do Solo, Campinas, v.19, n.1, p.87-94, jan./abr. 1995.

FERRARI NETO, J. Limitações nutricionais para o colonião (Panicum maximum Jacq) e braquiária (Brachiaria decumbens Stapf) em latossolo na região noroeste do Estado do Paraná. Lavras: ESAL, 1991. 126p. Dissertação de Mestrado.

FIDALSKI, J. Fertilidade do solo sob pastagens, lavouras anuais e permanentes na região noroeste do Paraná. Revista Unimar, Maringá, v.19, n.3, p.853-861, set. 1997. 
GOMES, J. de C. Considerações sobre adubação e calagem para a cultivar de mandioca. Revista Brasileira de Mandioca, Cruz das Almas, v.6, n.2, p.99-107, dez. 1987.

HOFFMANN, C.R.; FAQUIN, V.; GUEDES, G.A.A.; EVANGELISTA, A.R. O nitrogênio e o fósforo no crescimento da braquiária e do colonião em amostras de um latossolo da região noroeste do Paraná. Revista Brasileira de Ciência do Solo, Campinas, v. 19, n.1, p.79-86, jan./abr. 1995.

HOWELER, R.H. Long-term effect of cassava cultivation on soil productivity. Field Crops Research, Amsterdam, v.26, n.1, p.1-19, Mar. 1991.

HOWELER, R.H. Práticas culturais relacionadas ao solo na cultura de mandioca. In: SEMINÁRIO DE PRÁTICAS CULTURAIS DA MANDIOCA, 1., 1980, Salvador. Anais... Brasília: Embrapa-DDT, 1984. p. 95-112. (Embrapa-DDT. Documentos, 14).

LOZANO, J.C.; BELLOTTI, A.; REYS, J.A.; HOWELER, R.; LEIHNER, D.; DOLL, J. Problemas no cultivo da mandioca. Brasília: EMBRATER, 1983. 208p.
MARUN, F. Propriedades físicas e biológicas de um Latossolo Vermelho-Escuro do arenito Caiuá sob pastagem e culturas anuais. Pesquisa Agropecuária Brasileira, Brasília, v.31, n.8, p.593-597, ago. 1996.

MARUN, F.; MELLA, S.C. Recuperação de pastagens no noroeste do Paraná através da sucessão de culturas por um ano. Londrina: IAPAR, 1994. 15p. (IAPAR. Informe da Pesquisa, 111).

MARUN, F.; MELLA, S.C. Recuperação de pastagens pela sucessão de culturas anuais e bianuais; um estudo no noroeste do Paraná. Londrina: IAPAR, 1997. 24p. (IAPAR. Boletim técnico, 52).

PAVAN, M.A.; BINGHAM, F.T.; PRATT, P.F. Chemical and mineralogical characteristics of seleted acid soils of the State of Paraná, Brazil. Turrialba, San Jose, v.35, n.2, p.131-139, abr./jun. 1985.

PAVAN, M.A.; BLOCK, M. de F.; ZEMPULSKI, H. da C.; MIYAZAWA, M.; ZOCOLER, D.C. Manual de análise química de solo e controle de qualidade. Londrina: IAPAR, 1992. 40p. (IAPAR. Circular, 76) 